\title{
THE EFFECT OF NON-HYDROSTATIC STRESS ON INTERGRANULAR WATER VEINS AND LENSES IN ICE
}

\author{
By J. F. Nye and S. Mae \\ (H. H. Wills Physics Laboratory, University of Bristol, Bristol, England)
}

Abstract. Polycrystalline ice at the melting point has been observed in the laboratory to contain veins of water at the places where three grains meet. Under uniaxial compression lenticular water inclusions appeared at grain boundaries perpendicular to the stress, while the nearby vein began to freeze. A similar effect occurred in tension on grain boundaries parallel to the stress. When the stress on the plane of the boundary was a pure shear stress, no effect was observed. The water lenses produced by stress increased in size and decreased in number after the stress was removed. The effect under compression is explained quantitatively by the combined effects of curvature and pressure on the melting point of an ice-water interface. The rate of formation of the lenses and of their coarsening is greatly reduced by the internal pressures set up in the lenses as a result of expansion on freezing and contraction on melting; transient creep to accommodate volume changes is an essential part of the process. The effect in a grain boundary under tension may arise from pressure caused by sliding on other grain boundaries; it was absent in a bicrystal.

It is concluded that internal melting and freezing at grain boundaries and veins will occur in temperate glacier ice, with some effect, not discussed here, on its permeability to water. Any pure solid at its melting point which has a dihedral angle for the liquid phase in contact with a grain boundary between $0^{\circ}$ and $60^{\circ}$ should show similar behaviour, in that non-hydrostatic stress should cause liquid to move away from triple junctions between grains and into grain boundaries. There may be implications for the Frank theory of the upwelling of melt fluid in the Earth's upper mantle.

RÉsumé. Les effets des efforts non hydrostatiques sur les veines et lentilles d'eau intergranulaires dans la glace. On a observé en laboratoire que la glace polycristalline au point de fusion contient des veines d'eau aux endroits où trois grains se rencontrent. Sous une compression uniaxiale, des inclusions aqueuses lenticulaires apparaissent aux limites entre les grains, perpendiculairement à la direction de l'effort, alors que les veines voisines commencent à regeler. Un effet analogue se produit sous un effort de traction le long des limites des grains parallèles à l'effort. Lorsque l'effort sur le plan de la région frontière entre grains est un cisaillement pur, on n'observe aucun effet. Les lentilles d'eau produites par un effort s'accroissent en dimension et diminuent en nombre lorsque l'effort cesse. L'effet sous compression s'explique quantitativement par les effets combinés de la courbure et de la pression au point de fusion à une interface glace-eau. La vitesse de formation des lentilles et de leur grossissement est fortement réduite par les pressions internes dans les lentilles qui résultent de l'augmentation de volume dû au regel et de la contraction lors de la fusion ; les frottements transitoires pour s'adapter aux changements de volume sont un élément essentiel du processus. L'effet de la traction dans une zone limitée entre grains peut provenir de la pression causée par le glissement sur d'autres zones limites de grain; cet effet est absent dans un bicristal.

On en conclut que des fusions et regels internes aux limites des grains et des veines se produisent dans la glace de glacier tempéré, avec quelques conséquences qui ne sont pas discutées ici, sur sa perméabilité à l'eau. Un solide pur à son point de fusion qui a un angle diedre pour la phase liquide en contact avec une de grain entre $0^{\circ}$ et $60^{\circ}$ devrait montrer un comportement analogue, en ce sens qu'un effort non hydrostatique devrait pousser le liquide à s'éloigner des zones triples de jonctions entre les grains pour s'introduire dans les zones limites entre deux grains. Il peut y avoir là des implications pour la théorie de Frank pour le jaillissement de matières en fusion dans la partie supérieure de la croûte terrestre.

Zusammenfassung. Die Wirkung nicht-hydrostatischen Druckes auf intergranulare Wasseradern und Linsen in Eis. Bei Laborbeobachtungen wurde festgestellt, dass polykristallines Eis am Schmelzpunkt an den Berührstellen zwischen je drei Körnern Wasseradern enthält. Bei einachsiger Kompression traten linsenförmige Wassereinschlüsse an den Korngrenzen rechtwinklig zur Spannungsrichtung auf, während die benachbarte Ader zu gefrieren begann. Ein ähnlicher Effekt trat bei Zug an den Korngrenzen parallel zur Spannungsrichtung auf. Bei reiner Scherspannung auf der Grenzfläche trat keinerlei Wirkung ein. Die durch Spannung erzeugten Wasserlinsen nahmen nach Spannungsentzug an Grösse zu und an Zahl ab. Die Wirkungen unter Kompression werden quantitativ durch gemeinsame Einflüsse der Krümmung und des Schmelzdruckes einer Eis-Wasser-Grenzfläche erklärt. Die Geschwindigkeit der Linsenbildung und ihrer Vergrösserung wird weitgehend durch innere Spannungen verringert, die in den Linsen durch Ausdehnung beim Gefrieren und Kontraktion beim Schmelzen auftreten; zeitweiliges Kriechen zur Anpassung an die Volumänderungen ist ein wesentlicher Bestandteil dieses Prozesses. Die Wirkung an die Korngrenze bei Zugspannung kann durch Druck entstehen, der durch Gleiten an anderen Korngrenzen hervorgerufen wird; bei Bikristallen trat sie nicht auf.

Es wird angenommen, dass internes Schmelzen und Gefrieren an den Korngrenzen und Adern in temperiertem Gletschereis vorkommt, wobei Auswirkungen, die hier nicht diskutiert werden, auf seine Wasserdurchlässigkeit bestehen. Jeder reine Körper, der einen spitzen Winkel zwischen $o^{\circ}$ und $60^{\circ}$ für die flüssige Phase in Kontakt mit einer Korngrenze aufweist, sollte am Schmelzpunkt ähnliches Verhalten zeigen; denn nicht-hydrostatischer Druck sollte Flüssigkeit veranlassen, sich von Tripelpunkten zwischen Körner weg und in Korngrenzen zu bewegen. Es könnten Verbindungen zur Frank'schen Theorie des Aufquellens von Schmelzflüssigkeit im oberen Erdmantel bestehen. 


\section{INTRODUCTION}

The geometry of the water phase in pure polycrystalline ice in equilibrium at the melting point has been deduced by Nye and Frank (in press) from considerations of surface energy and from measurements by Ketcham and Hobbs (r 969 ) of the dihedral angle of water at a grain boundary. Nye and Frank concluded that the water was situated in veins at the threegrain junctions, and that the veins join together in fours at the four-grain junctions to form tetrahedra with concave non-spherical faces and open corners. This conclusion was supported by observations of ice specimens in the laboratory, and they went on to propose that a temperate glacier is filled with a three-dimensional network of veins of water between the grains. The ice was therefore permeable to water which, by draining downwards through the vein system, might provide an efficient means of flushing impurities into and out of the glacier. More recently Lliboutry (I97I) has considered the important effects that soluble impurities will have on the permeability of temperate glacier ice and he has given some consideration to the effect on liquid inclusions of plastic deformation and non-hydrostatic stresses. Some experimental evidence bearing on these questions has been provided by Barnes and Tabor (r968), who concluded from indentation tests on polycrystalline ice that pressure melting could occur under these conditions at grain boundaries.

Before the present experiments began Professor F. C. Frank pointed out in discussion that a shear stress would tend to cause extremely high concentrations of stress at the (molecularly) sharp edges of veins in temperate ice, and he discussed the possibility of water being forced out of the veins and into the grain boundaries by freezing and melting. In this paper we describe and interpret laboratory observations on the behaviour of veins in ice when they are subjected to non-hydrostatic stress. A flowing glacier is necessarily in a state of non-hydrostatic stress, and if this has an effect on the vein system it is one more factor to be considered in the current debate about the permeability of temperate glaciers.

\section{ExPERIMENTAL PROcedure}

\section{I. Test specimens}

Cylindrical ice blocks (diameter $80 \mathrm{~mm}$, length $120 \mathrm{~mm}$ ) were grown from distilled water in a metal container, evacuated to avoid the formation of air bubbles. The conductivity of the melt water of the grown ice was $7 \times \mathrm{IO}^{-5} \Omega^{-1} \mathrm{~m}^{-1}$ at $\mathrm{O}^{\circ} \mathrm{C}$ (this compares with

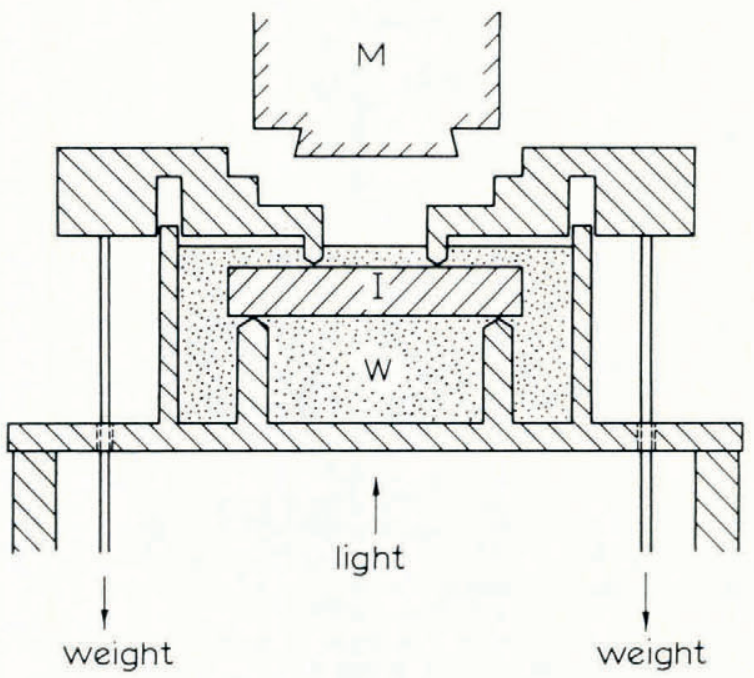

Fig. I. Four-point bending apparatus. I: ice specimen, $M:$ microscope, W: water bath. 
a range of about ( $\mathrm{I}$ to 25 ) $\times \mathrm{IO}^{-4} \Omega^{-1} \mathrm{~m}^{-1}$ at $\mathrm{O}^{\circ} \mathrm{C}$ for the melt water of glacier ice). The ice consisted of clear candle-shaped grains, elongated in the growth direction, 5 to $20 \mathrm{~mm}$ in size, with $c$-axes roughly perpendicular to the growth direction; thus many of the veins were roughly perpendicular to the $c$-axes of the three adjacent grains. The test specimens cut from the blocks were cubes $\left(20 \times 20 \times 20 \mathrm{~mm}^{3}\right)$ for the indentation experiments and rectangular bars $\left(\mathrm{i} 0 \times \mathrm{i} 6 \times 60 \mathrm{~mm}^{3}\right)$ for the bending experiments.

\subsection{Methods of loading}

Three kinds of loading were used: indentation, three-point bending and four-point bending. Indentation was chosen for the first experiment with the object of producing a wide variety of stress conditions and thus discovering whether stress had any observable effect on the veins. An effect was found and we then wished to examine separately the effects of pure tension, pure compression and pure shear stress acting across a grain boundary. The purpose of the three-point bending was to produce a shear stress unaccompanied by any hydrostatic stress; this condition exists on the neutral axis of the specimen. The purpose of the four-point bending experiments was to produce pure tension on one side of the neutral plane and pure compression on the other.

The devices for producing these three kinds of loading were all made of perspex (polymethyl methacrylate). The four-point bending device is shown in Figure $\mathrm{I}$; the others were basically similar. In each case the ice specimen was immersed in a water bath which was kept at $0^{\circ} \mathrm{C}$ by adding ice, the whole apparatus being in a commercial deep-freeze cabinet regulated to $0^{\circ} \mathrm{C}$. The specimen was observed with a microscope through the free top surface of the water. In this way the optical effect of the unevenness of the top surface of the ice specimen is minimized because most of the refraction occurs at the flat water-air interface and comparatively little at the more uneven ice-water interface. The heat radiation from the microscope lamp was removed with a filter.

\section{Observations}

\subsection{Indentation}

Figures $2 \mathrm{a}$ and $\mathrm{b}$ show the effect on a vein of indenting the specimen; they are typical of a number of similar observations. Figure $2 \mathrm{a}$ was taken before indentation. The vein is the central vertical line. The three dark lines meeting at the top are three out-of-focus grain-boundary grooves in the top surface of the specimen. The vein runs from their intersection down into the specimen and the plane of focus of the microscope passes through the vein about half-way down the photograph. The indenter was then pressed down with a screw device. Figure $2 b$ shows the appearance ros later. The part of the vein below the plane of focus has disappeared and small water inclusions have appeared in the grain boundary to the right of the vein. The indentation itself is outside the picture to the upper left $(7 \mathrm{~mm}$ from the vein).

The large water inclusions visible in the upper left corner of Figure $2 b$ were formed inside a grain rather than at a grain boundary. They represent a different type of phenomenon from the one we are concerned with in this paper. Close to the indenter cracks parallel to the basal planes of the crystals are seen to form; at first some parts of them are filled with vapour, but after about one minute they are completely filled with water, which collects in irregularly shaped patches.

\subsection{Shear stress}

Having established by the indentation experiments that an applied stress could have a marked effect on a vein, we examined the effect of applying a shear stress parallel to a grain boundary. This was done by using the three-point bending apparatus. In Figure 3, with 


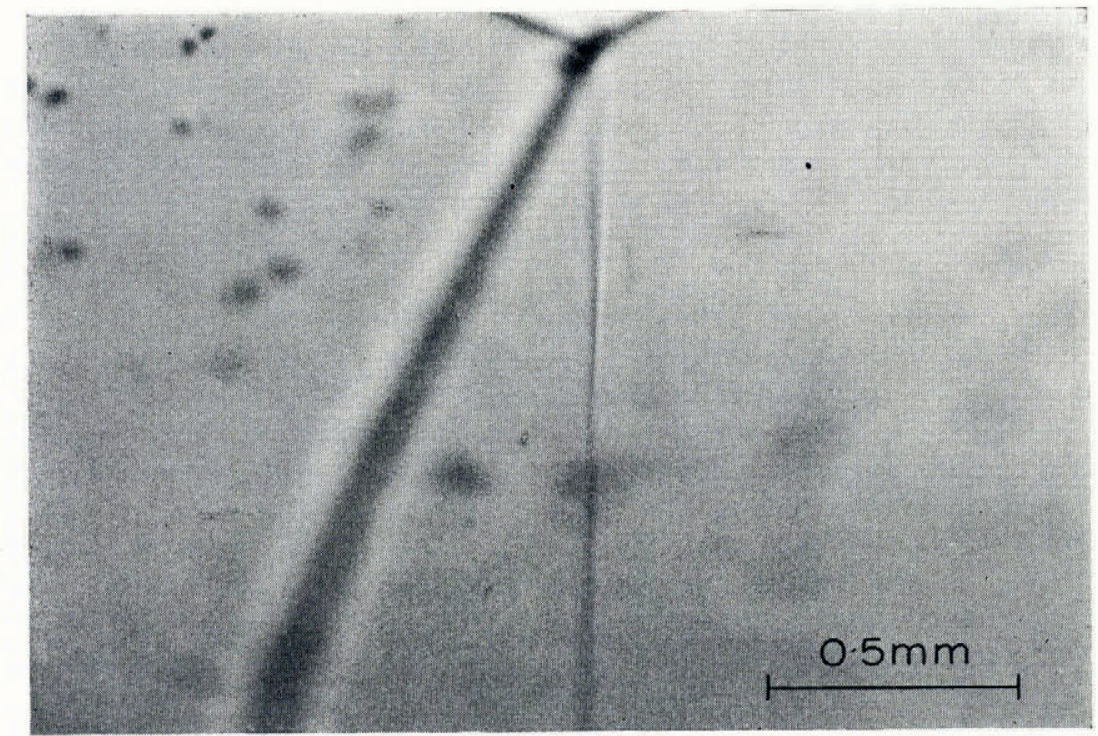

Fig. 2a. Before indentation. The vein is the central vertical line.

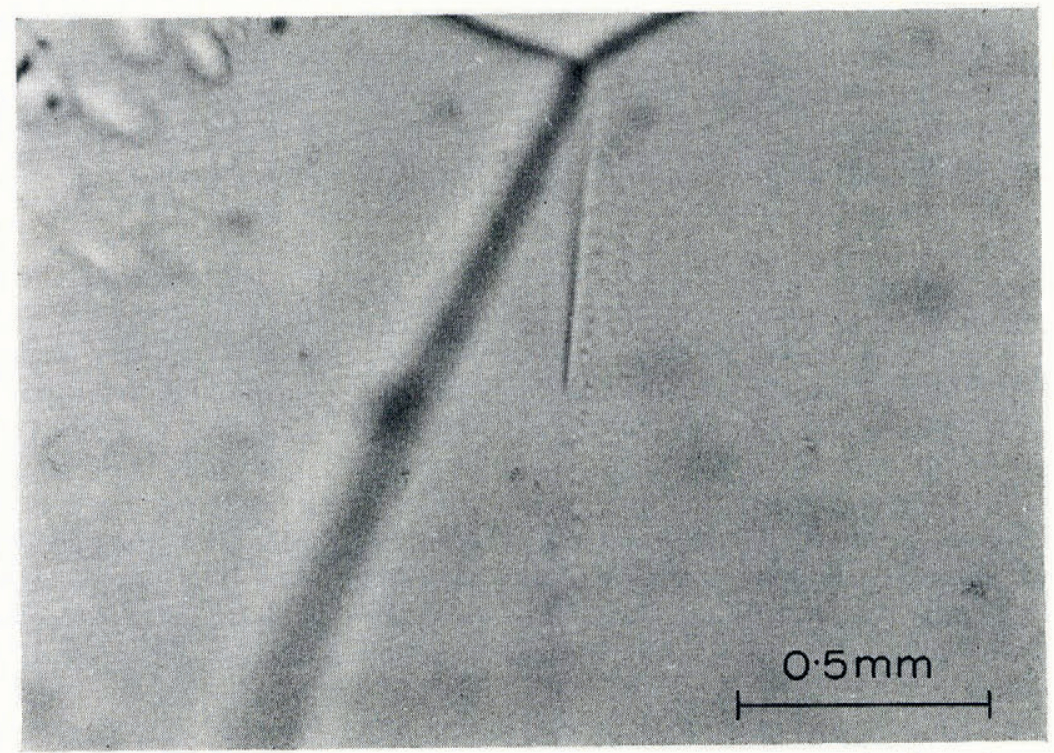

Fig. 2b. Io s after indentation. Water inclusions have appeared to the right of the vein.

the axes shown, the stress at points on the plane $y=0$, not close to the knife-edges, may be estimated by assuming isotropic elasticity as $\tau_{x y}={ }_{3} W / 8 a c$, with all other stress components zero, where $a$ is the width of the specimen, $2 c$ is its thickness and $W$ is the load applied to the upper central knife-edge.

We observed grain boundaries that lay close to the plane $y=0$ and parallel to it, and which were therefore bounded by veins lying in various directions in the $x z$ plane. On these grain boundaries, which were subject only to shear stress, no effect of the stress was observed, the maximum shear stress applied being 0.7 bar. We also observed, close to the 


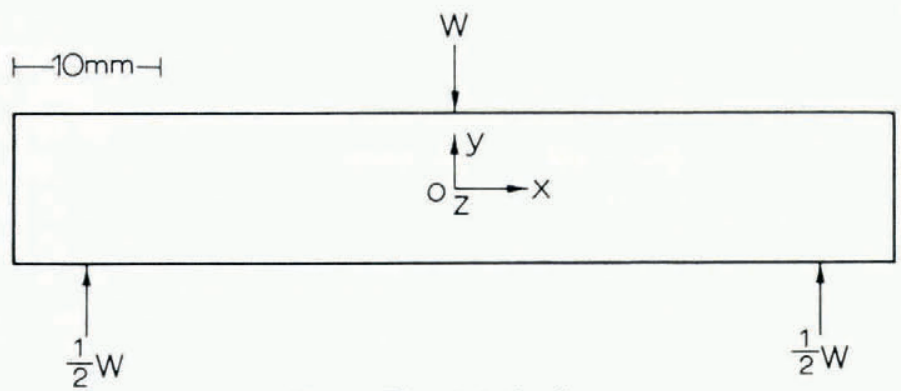

Fig. 3. Three-point bending.

plane $y=0$, other grain boundaries whose normals lay in various directions in the $y z$ plane. The stress acting across these boundaries is also entirely tangential, there being no normal components either normal or parallel to the grain boundary. Again there was no observable effect.

On the other hand, at the plane $y=0$ grain boundaries having normals in the $x y$ plane did show an effect. These grain boundaries are not subject to shear alone and the effect on them will be described in Section 3.4.

We conclude that a shear traction of up to 0.7 bar acting across a grain boundary has no observable effect regardless of the angle it makes with a vein.

\subsection{Tensile and compressive stress}

The four-point bending apparatus gave the opportunity of examining the effect of pure tension and pure compression. It was found that, on the compression side of the specimen, lens-shaped water inclusions were formed in those grain boundaries that lay roughly perpendicular to the stress axis (Fig. 4a), while on the tensile side similar water inclusions appeared in those boundaries that lay roughly parallel to the stress axis (Fig. 4b); we shall call them "lenses" from now on. Figure 5 a shows an example. The plane of focus of the microscope is below the surface of the specimen. The blurred lines are out-of-focus grainboundary grooves on the surface. Thus one of the grain boundaries starts at the nearly

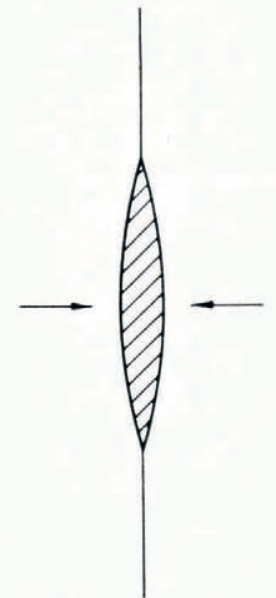

(a)

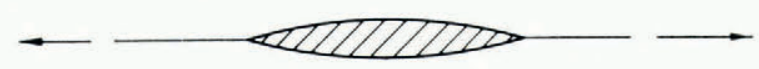

(b)

Fig. 4. Lenses form in grain boundaries (a) perpendicular to a compressive stress or $(b)$ parallel to a tensile stress. 
horizontal grain-boundary groove running across the centre of the picture and dips down towards the bottom of the picture. The tensile stress resulting from the bending was parallel to this grain boundary (within $5^{\circ}$ ) and was applied for $2400 \mathrm{~s}$. Lenses can be seen just below the grain-boundary groove. Very many more lenses were present than are visible in the photograph; the depth of focus is such that only a few can be seen in focus at any one setting. By focusing up and down it could be seen that the lenses formed preferentially near veins or near grain-boundary grooves. Figure $5 \mathrm{~b}$ shows the same area, but the sign of the stress has been reversed: following the tension an equal compressive stress in the same direction has been applied for $600 \mathrm{~s}$. Lenses have now appeared in the grain boundary on

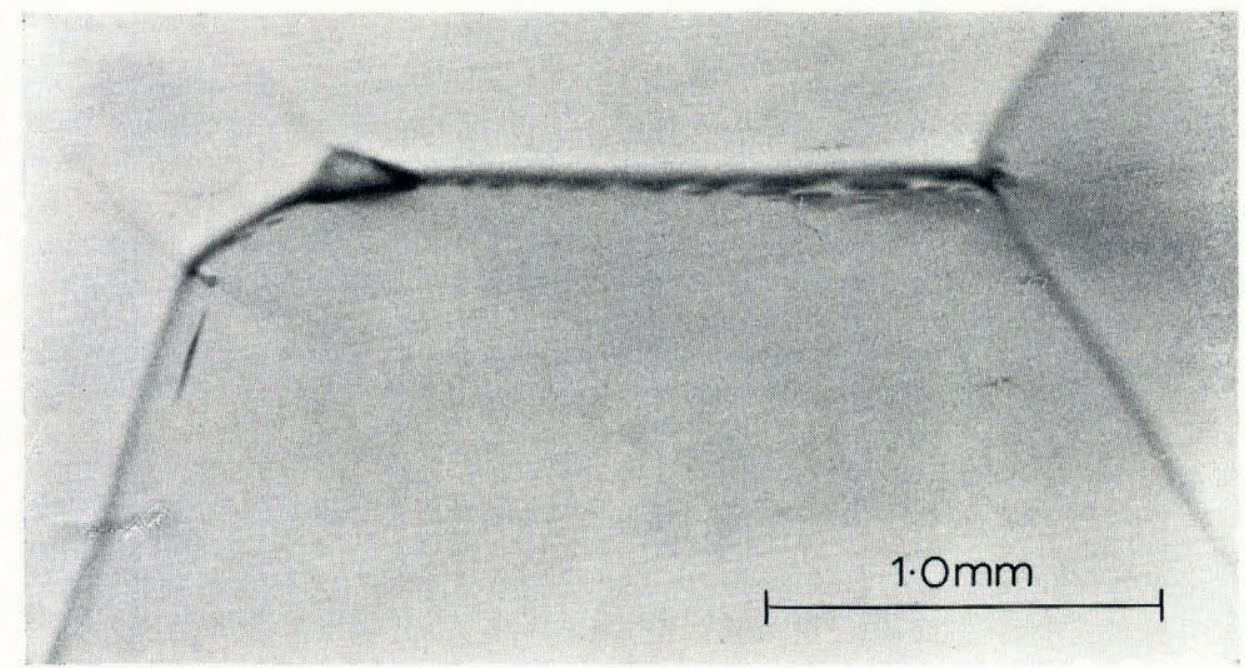

Fig. 5a. A tensile stress of 2.6 bar was applied for 40 min parallel to the central horizontal grain boundary. The photograph was taken I min later. Water lenses are seen just below the grain-boundary surface groove.

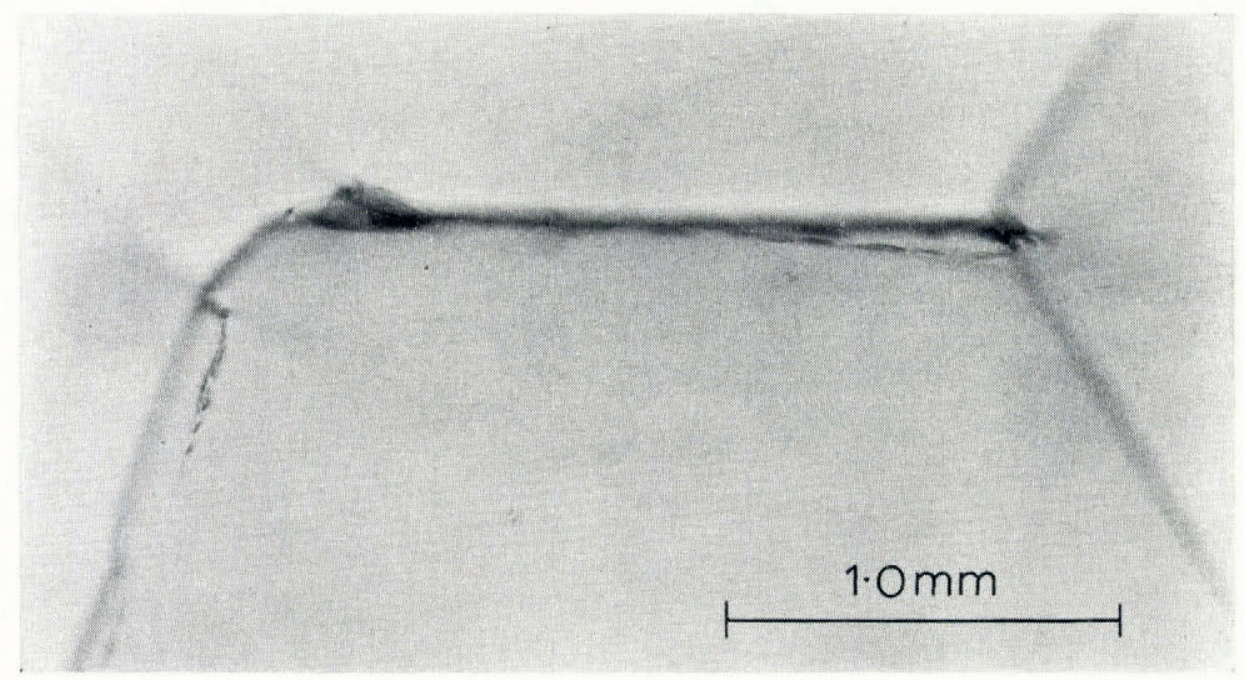

Fig. $5 b$. The same as Figure $5 a$. The tensile stress was replaced by an equal compressive stress applied for 10 min. Water lenses have appeared in the grain boundary on the left, perpendicular to the stress. 
the left nearly perpendicular to the stress. Once again there were many other lenses lying out of the plane of focus that are not visible in the photograph.

While the lenses were forming the neighbouring veins were seen to shrink, and sometimes to disappear. They did not always shrink homogeneously. The time needed for the veins to disappear completely depended on the stress. With the very high but unmeasured stress produced by indentation the time was about ios; with a tensile or compressive stress of $\mathrm{I} .3$ bar produced by four-point bending the time was about $\mathrm{roo} \mathrm{s}$.

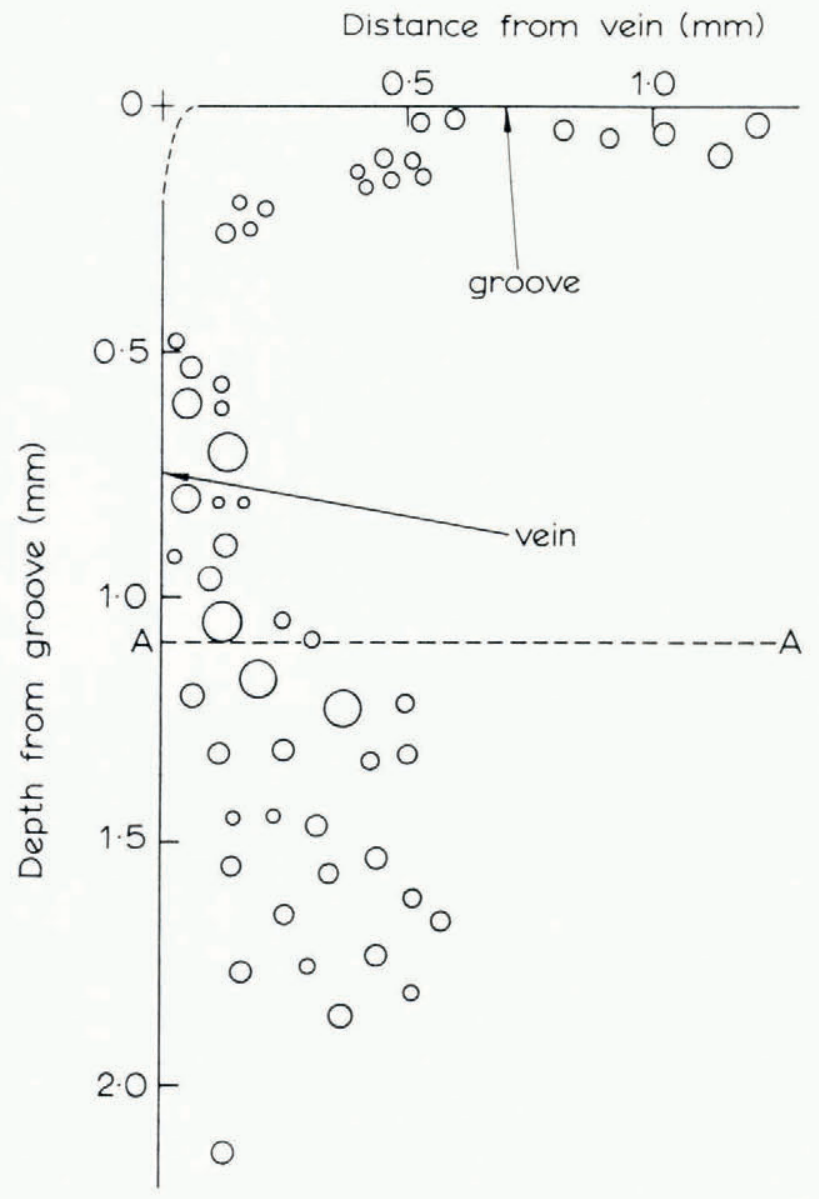

Fig. 6. A map of the water lenses in the grain boundary shown in the centre of Figure 7a. AA is the plane of focus for Figure $7 a$.

The distribution of lenses in a particular grain boundary that has been subject to uniaxial compression is shown in Figure 6. They lie in a strip about $0.15 \mathrm{~mm}$ wide immediately under the surface groove and also in a rather wider strip, up to $0.6 \mathrm{~mm}$ wide, alongside the vein. The scarcity of lenses near the upper part of the vein is compensated by a comparative excess in one of the other two grain boundaries. Figure 7 a is a photograph of the grain boundary of Figure 6 with the plane of focus of the microscope at the depth marked AA. The dark out-of-focus patch is the outcrop of the vein on the surface; three out-of-focus grain-boundary grooves radiate from it; the vein (barely visible) extends to the left and, 
running slightly downwards in the picture, is a cluster of lenses that lie in the grain boundary mapped in Figure 6. Further lenses in a second grain boundary can be seen on the right of the vein. There are none in the third grain boundary, which is parallel to the compression axis, as expected.

The times taken for lenses to form in a given grain boundary near a vein and near the surface groove were not noticeably different. Compression perpendicular to a boundary

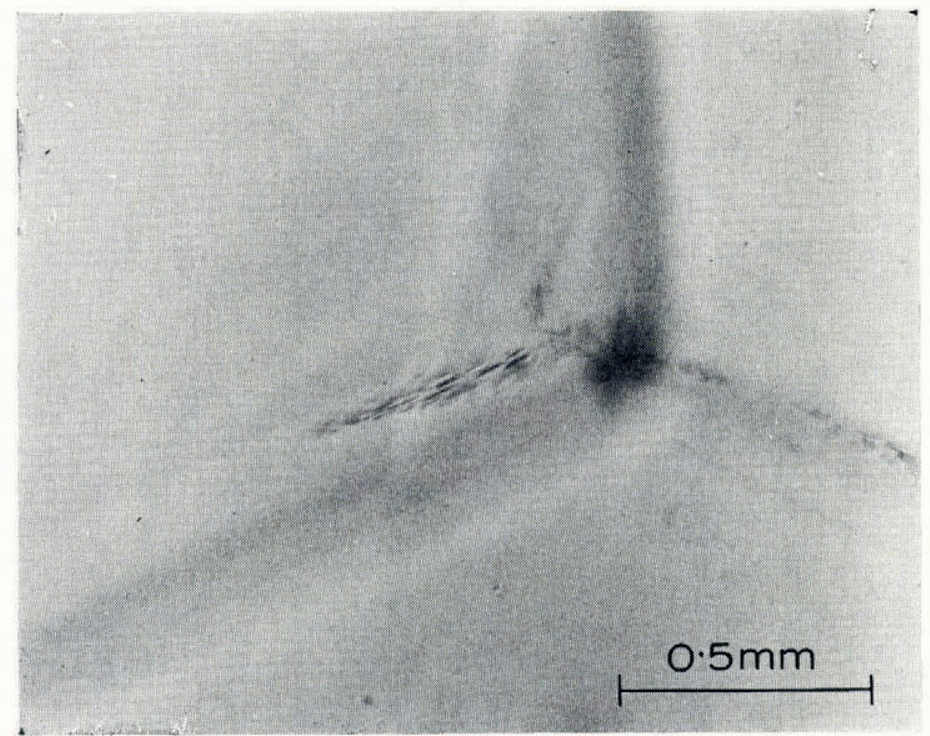

Fig. 7a. A compressive stress of 1.3 bar was applied for $100 s$ in the direction that appears vertical in the photograph. The photograph was taken a few seconds after removal of the load. Water lenses appear in the two roughly horizontal grain boundaries but not in the vertical one.

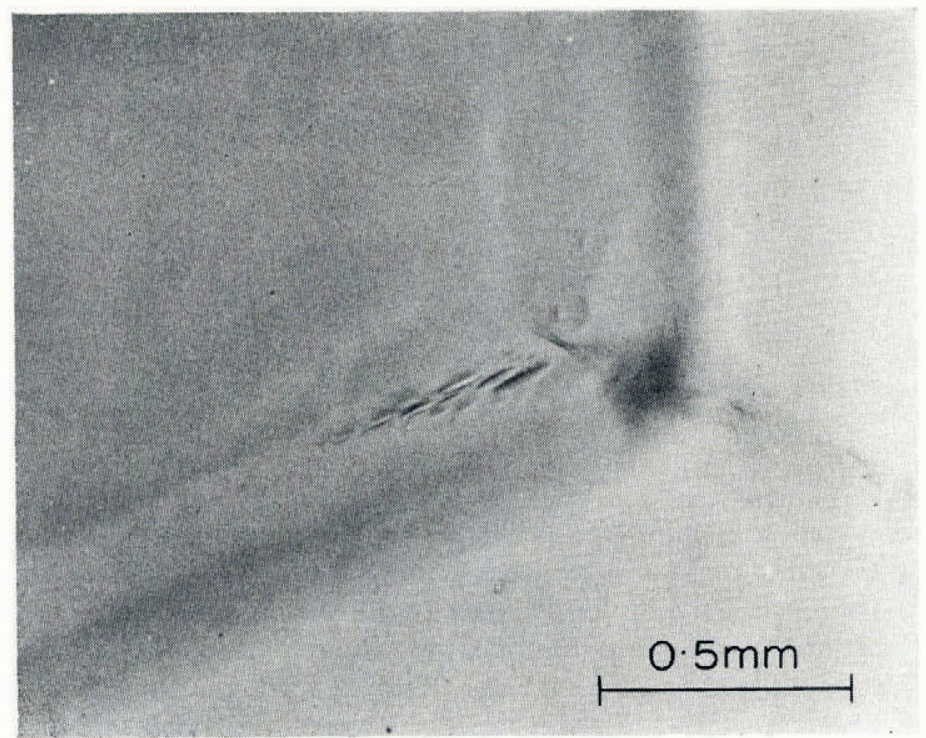

Fig. 7 b. The same as Figure 7 a after annealing without load for one hour. 
was more effective than tension parallel to a boundary, in the sense that for equal times of application a compressive stress produced larger lenses and more of them than an equal tensile stress.

\subsection{Combined tension and compression}

We have said already that in the three-point bending experiments no water lenses formed on grain boundaries that were subject only to shear stress. At the plane $y=o$ (Fig. 3) we also observed grain boundaries having normals in the $x y$ plane and inclined both to the $x$ and $y$ axes. For example, a grain boundary inclined at $45^{\circ}$ to the $x$ axis would have either a compression acting across it and a tensile stress acting in its plane, or a tensile stress acting across it and a compressive stress acting in its plane. In the first case both the normal stress and the stress in the plane of the grain boundary would be expected, on the basis of the previous observations, to produce lenses. Lenses were in fact formed in such boundaries. In the second case neither of the two stresses should produce lenses, and in fact none was observed.

Thus the conditions under which lenses are formed at the grain boundaries are summarized by Figures $4 \mathrm{a}$ and $\mathrm{b}$.

\subsection{Annealing}

Figure $7 \mathrm{~b}$ was taken $\mathrm{I} \mathrm{h}$ after Figure $7 \mathrm{a}$, no stress being applied during this time. As is apparent, the number of lenses has decreased and those remaining are larger. There was no change in the total volume of the lenses during this process, to an accuracy of about $5 \%$. Since ice contracts on melting we looked for any evidence for the formation of vapour cavities while the water lenses were forming or annealing. No vapour cavities were seen.

\section{Discussion}

\section{I. Effect of compression}

Figure 8a shows a lens-shaped water inclusion at a grain boundary near a vein, while Figure 8b shows a similar lens near a grain-boundary groove (it should be remembered that the ice specimens were immersed in water). As discussed by Nye and Frank (1971) the three curved surfaces of the vein are taken to be parts of circular cylinders, while the surfaces of the lens are taken to be spherical. The geometry is fixed by the constant dihedral angle $2 \theta$ in the water phase where it meets a grain boundary. If one ignores the dependence of surface energy upon crystallographic orientation, the balance of surface energies gives

$$
\cos \theta=\frac{\gamma_{\mathrm{gb}}}{2 \gamma}
$$

where $\gamma_{\mathrm{gb}}$ and $\gamma$ are the specific surface free energies of the grain boundary and the icewater interface respectively.

The ice-water interfaces will be at their respective melting points, and, in the absence of any stress, the melting point is determined by the curvature of the interface and by the impurity concentration. If we assume that the concentration of impurities is the same in the lens as in the vein or groove, the melting point at the lens, which has surfaces concave on the water side, will be higher than that at the vein or groove. Heat will therefore flow away from the lens, which will freeze, and a corresponding amount of ice will be melted at the vein or groove. So such lenses will not survive. If, however, a compressive stress $P$ is applied perpendicular to the grain boundary the melting points will be different. Let us consider first the lens near the groove (Fig. $8 \mathrm{~b}$ ). As a result of the applied stress a certain excess pressure will be set up in it and the temperature of the interface will be lower than before; 
at the same time the pressure and therefore the temperature at the groove remains unaltered. Let the pressure in the lens be $p$. We shall discuss the relation between $P$ and $p$ in detail later; here we need only note that as $P$ increases so will $p$, and, at a value of $p$ determined by the curvature of the interfaces, the melting point of the lens will become lower than that of the groove, heat will flow towards it, and it will tend to grow. If the lens were very small, the curvature of its faces would be very high, and so the pressure required for growth would be very high. For a given applied pressure there will therefore be a critical size above which lenses will grow and below which they will shrink. We show in

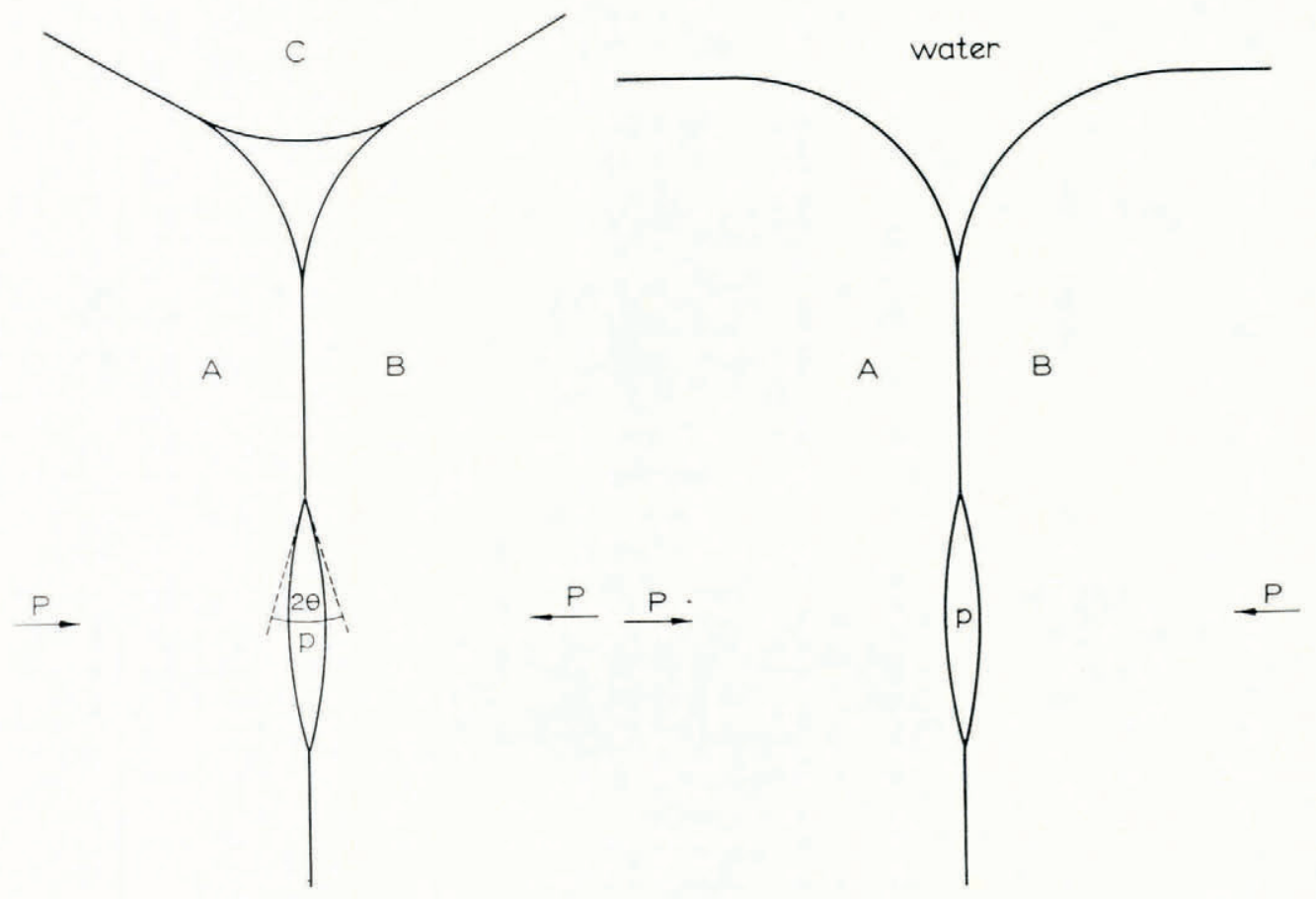

(a)

(b)

Fig. 8. A water lens (a) near a vein and $(b)$ near a surface groove. $A, B$ and $C$ denote ice grains.

Section 5.2 that the sizes of lenses observed are consistent with the compressive stress actually applied. It may well be that the water lenses nucleate on impurities in the grain boundary, and if there is a relatively high concentration of impurities in the lenses of course they will grow more easily.

If the lens is near a vein (Fig. 8a) rather than near a surface groove, the situation is different in at least two respects. First we have to consider what effect the applied stress $P$ will have on the pressure of the water within the vein. In the experiments the veins were in communication with the surrounding water bath. If the pressure in the vein were to exceed atmospheric pressure, water would flow out of it towards the surface against viscous forces, but a calculation shows that in the experiments the viscous forces are quite insufficient to allow a significant pressure difference to be set up in this way - and so the situation is the same as for a groove. On the other hand, if the path to the free surface were long enough (say roo $\mathrm{m}$ ), as it could be in a glacier, the pressure in the vein could be raised by the applied stress and we discuss this possibility in Section 6. 
The second point of difference in the case of the vein is that as a lens grows by melting the vein will shrink by freezing; its cross-section remains geometrically similar and so the curvature of its faces will increase. Its impurity concentration will also increase as it freezes. Both these effects will lower its melting point and hence its temperature, the temperature difference driving the heat towards the lens will decrease, and the lens will eventually stop growing. This restriction is not present so acutely with the surface groove because there is much less tendency for freezing near the groove to accentuate its curvature or the local impurity concentration.

The observation that a vein under stress can disappear from view does not, we believe, imply that the vein has actually frozen completely. The two effects just described, increase of both curvature and impurity concentration, will prevent complete freezing. It is therefore most likely that the vein has simply shrunk below the size at which it is visible in the microscope.

The fact that a $10 \%$ change of volume occurs on melting or freezing is a major complication in understanding and explaining all these phenomena. As a lens grows, the contraction on melting will tend to reduce the pressure within it. Further melting can only occur if this $10 \%$ volume contraction is accommodated by plastic deformation. The short times $(\approx \mathrm{I} 00 \mathrm{~s})$ involved mean that the plastic deformation process will be transient creep. The pressure $p$ within the lens will be that which, acting in conjunction with the applied uniaxial pressure $P$, is sufficient to produce the required plastic creep contraction around the lens (note that $P$ tends to contract the liquid-filled cavity, while $p$, being greater than atmospheric pressure, tends to expand it). The implied plastic deformation problem, the deformation of a melting cavity with sharp edges under a simultaneous internal pressure and external uniaxial compressive stress, is a very difficult one, even more so since transient creep is involved. Fortunately, as we shall see in Section 5.3 , it is possible to draw conclusions about the relation between $P$ and $p$ without solving it, by considering the thermal half of the problem rather than the plastic deformation half of it.

\subsection{Annealing}

The effect shown in Figures $7 \mathrm{a}$ and $\mathrm{b}$ and described in Section 3.5 may be explained as follows. The dihedral angle being fixed, all the lenses are the same shape, differing only in scale. The interfaces are at their respective melting points corresponding to their different curvatures. A lens that is smaller than average will be hotter than average, and will therefore lose heat to the others. It will then contract by freezing, while the others grow a little by melting. This will continue until it disappears.

Because of the change in volume that necessarily occurs on freezing, the pressure in the contracting lens will be greater than that of its surroundings (we shall show in Section 5.4 that the surroundings are at a pressure greater than atmospheric) and this will have the effect of making it less hot than it would otherwise be; it will slow down the transfer of heat.

The pressures thus set up in the lenses will be those that produce transient creep rates that are just sufficient to accommodate the volume changes demanded by the heat flow. The differential pressures may be calculated by considering the heat flow problem (rather than the creep problem). We show in Section 5.5 that, if the differential pressure is assumed negligible, so that the need for plastic creep offers no appreciable obstacle to the annealing process, annealing should proceed $1 \mathrm{O}^{3}$ times faster than is actually observed. However, a differential pressure of only about 0.03 bar is enough to slow down the annealing rate to the value observed. We conclude that this small differential pressure is present, and that it causes the amount of plastic deformation needed to accommodate the volume changes. 


\subsection{Effect of tension}

The effect of tension in producing lenses (Fig. 4b) is more difficult to explain than the effect of compression (Fig. 4a). Consider, for example, the lenses produced under tension near a grain-boundary groove at the surface of the specimen. There is no question here about what is the pressure in the groove; it is atmospheric. The water lens must have a lower melting point, in spite of its curvature which gives it a high melting point relative to the groove. The only way in which this low melting point can be produced is by a pressure within the water (the effect is produced by applied stress, so although impurities may help they are not primarily responsible). A tension in the manner of Figure $4 \mathrm{~b}$ may tend to close up a lens-shaped inclusion and thus set up a pressure in it. We at first believed that this was the reason for the melting, but the following rather different explanation now seems to us more plausible, although we still remain a little sceptical of it.

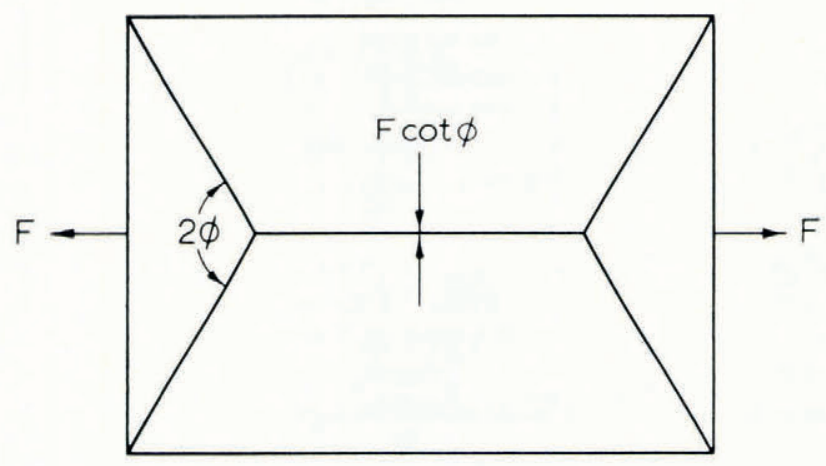

Fig. 9. Model where longitudinal tension produces transverse compression.

The problem is to explain how a tension parallel to a boundary can produce a compressive stress perpendicular to it. Consider the specimen in Figure 9, where the lines are grain boundaries, and suppose, as an extreme case, that slip can occur quite freely along the grain boundaries, so that they can sustain normal tractions but not tangential tractions. Statical considerations then show that the forces $F$ applied to the ends will produce a compressive force $F \cot \phi$ across the central grain boundary, where $\phi$ is the angle shown; the triangular end grains act as wedges, but in reverse. If the grain boundaries are endowed with some resistance to shear the compressive force is reduced; $F \cot \phi$ is the maximum possible. In this model the lateral surfaces of the specimen are free; a model more appropriate to a specimen with a smaller grain size is illustrated in Figure ro. If this specimen is under horizontal tensile stress $\sigma$ and the grain boundaries are weak in shear, there will be compression across $\mathrm{AB}$ and, by a similar mechanism, tension across the line $\mathrm{CD}$ in the grain interior. For a calculation assume that the grains are regular hexagonal prisms, that the grain boundaries can carry shear traction $k$ and that the average tensile stress across CD is one half of the average compressive stress $p_{0}$ across $\mathrm{AB}$ (since $\mathrm{CD}=2 \mathrm{AB}$ and all grains are alike, this ensures that the total lateral force acting across the longitudinal line of which $\mathrm{AB}$ is a part is zero). Simple statics gives

$$
p_{0}=\frac{1}{2} \sigma-\frac{2}{\sqrt{ } 3} k
$$

Thus the maximum possible lateral compression across the grain boundaries, when $k=0$, is $\frac{1}{2} \sigma$. 
To test whether the effect observed was caused in this way we prepared a bicrystal with the grain boundary running down its full length. It was subjected to four-point bending and observed on the tensile side. No lenses could be seen near the grain-boundary groove. Two similar specimens gave the same result. We are therefore inclined to attribute the lenses seen under tension in Figure 5 a beneath the horizontal grain-boundary groove to the presence of the two grains lying to the left and right.

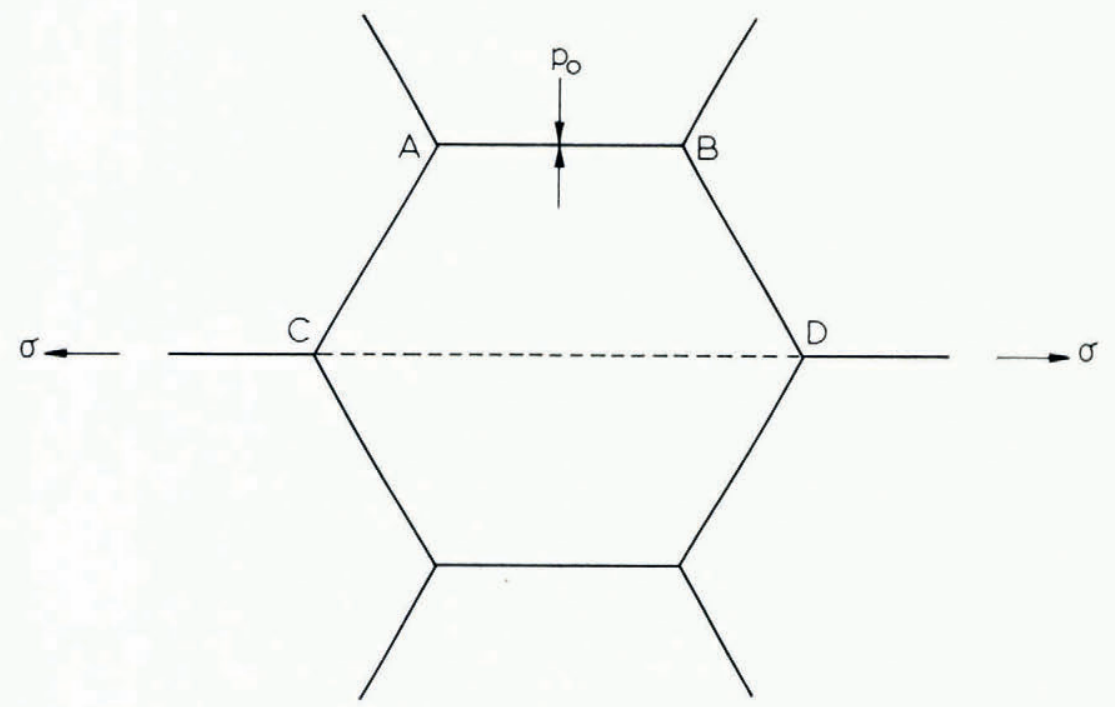

Fig. Io. The same as Figure 9 but with a smaller grain size.

\section{Detailed calculations}

\section{I. Geometrical relations}

The cross-sections of the veins and lenses are fixed by the dihedral angle $2 \theta$ and there are certain geometrical relations that we shall need. The volume $V_{\mathrm{v}}$ of unit length of a vein is given by

$$
V_{\mathrm{v}}=\left\{\sqrt{ } 3 \sin ^{2}\left(\frac{1}{6} \pi-\theta\right)+\frac{3}{2} \sin 2\left(\frac{1}{6} \pi-\theta\right)-3\left(\frac{1}{6} \pi-\theta\right)\right\} r_{\mathrm{v}}^{2}=\alpha r_{\mathrm{v}}^{2},
$$

and the volume $V_{1}$ of a lens is given by

$$
V_{1}=\frac{2}{3} \pi\left(\cos ^{3} \theta-3 \cos \theta+2\right) r_{1}^{3}=\beta r_{1}^{3}, \text { say, }
$$

where $r_{\mathbf{v}}$ is the radius of curvature of a cylindrical face of the vein and $r_{1}$ is the radius of curvature of the spherical faces of a lens.

In evaluating the constants $\alpha$ and $\beta$ numerically we do not adopt the value $2 \theta=20^{\circ} \pm 10^{\circ}$ reported by Ketcham and Hobbs (1969), for the following reason. A vein becomes considerably enlarged very near the surface so that it appears as shown in Figure II. It is funnelshaped rather than having a uniform cross-section. Ketcham and Hobbs measured the angles of the cross-section at the surface as seen in the microscope; but since the edges of the vein are not parallel to the line of sight the angle measured in this way will necessarily be less than the true dihedral angle. We conclude from their observations that $2 \theta>20^{\circ}$. On the other hand, the existence of veins within the specimen implies that $2 \theta<60^{\circ}$ as discussed by Nye and Frank (in press). 
The fact that the water inclusions produced in the present experiments are lens-shaped, and therefore have a focal length, provides a way of measuring $2 \theta$. Our colleague $\mathrm{Dr}$ M. E. R. Walford has observed the optical focusing effect of the water lenses and reports as a preliminary result $2 \theta=32^{\circ}\left( \pm 3^{\circ}\right)$. We shall use this value in what follows; it gives $\alpha=0.0725, \beta=0.0093 \mathrm{I}$. (A change in $2 \theta$ from $20^{\circ}$ to $32^{\circ}$ means that the value of the surface energy $\gamma$ derived by Ketcham and Hobbs should be changed from 33 to $34 \mathrm{~mJ} \mathrm{~m}^{-2}$, and we shall therefore use this latter figure for calculation.)

$r_{\mathrm{v}}$ and $r_{1}$ are related to the quantities observed in the experiments, namely the distance $d_{\mathbf{v}}$ between any two edges of a vein and the diameter $d_{1}$ of a lens, as follows:

$$
\begin{aligned}
r_{\mathbf{v}} & =d_{\mathbf{v}} / 2 \sin \left(\frac{1}{6} \pi-\theta\right), \\
r_{1} & =d_{1} / 2 \sin \theta .
\end{aligned}
$$

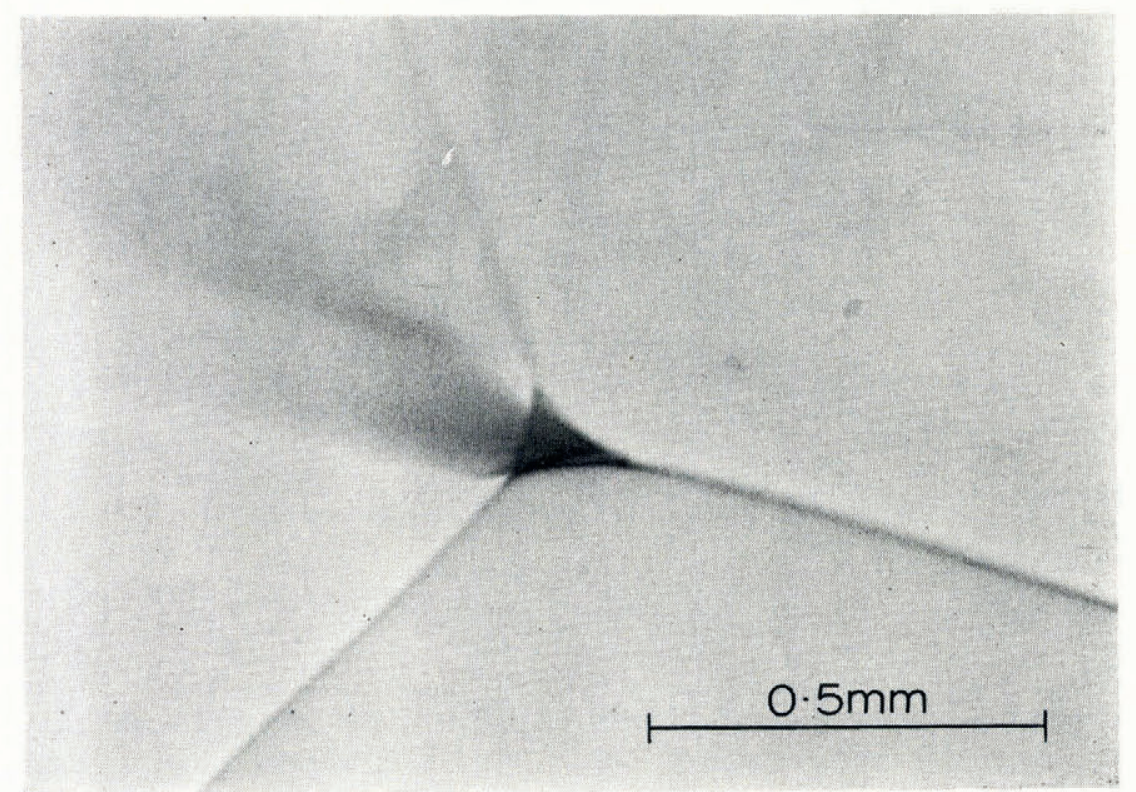

Fig. II. The outcrop of a vein at the surface of a specimen. Three grain-boundary grooves radiate from it.

\subsection{Critical pressure for the growth of a lens}

Consider the configuration of Figure $8 \mathrm{a}$. The combined effect of pressure and curvature is to change the melting point of the surface of a lens to $T_{1}$ where

$$
\mathcal{T}_{1}-\mathcal{T}_{0}=\frac{v_{\mathrm{i}}}{s_{\mathrm{W}}-s_{\mathrm{i}}} 2 \gamma \kappa_{1}+\frac{v_{\mathrm{W}}-v_{\mathrm{i}}}{s_{\mathrm{W}}-s_{\mathrm{i}}}\left(p-p_{0}\right) ;
$$

$T_{0}$ is the normal melting point, for pressure $p_{0}$ and zero curvature, $v_{\mathrm{W}}, v_{\mathrm{i}}$ and $s_{\mathrm{W}}, s_{\mathrm{i}}$ are the specific volumes and entropies of water and ice respectively, $\kappa_{1}=r_{1}^{-1}$ (taken positive) is the curvature and $p$ is the pressure in the water. (The stress component $p_{\mathrm{i}}$ in the ice normal to the surface is less than $p$ by an amount $2 \gamma \kappa_{1}$ because of surface tension. When written in terms of $p_{\mathrm{i}}$ rather than $p$ Equation (5) becomes

$$
T_{1}-T_{0}=\frac{v_{\mathrm{w}}}{s_{\mathrm{w}}-s_{\mathrm{i}}} 2 \gamma \kappa_{1}+\frac{v_{\mathrm{w}}-v_{\mathrm{i}}}{s_{\mathrm{w}}-s_{\mathrm{i}}}\left(p_{\mathrm{i}}-p_{0}\right) .
$$


The difference between $p$ and $p_{\mathrm{i}}$ in the present application is at most $2 \times 10^{-2}$ bar and can usually be ignored.) We have omitted from Equation (5) terms quadratic in the stress components, arising from the elastic energy, as being negligible at the stresses we are using.

The melting point $T_{\mathrm{v}}$ for the surface of a vein is given in a similar way by

$$
T_{\mathrm{v}}-T_{0}=-\frac{v_{\mathrm{i}}}{s_{\mathrm{w}}-s_{\mathrm{i}}} \gamma \kappa_{\mathrm{v}}
$$

where $\kappa_{\mathrm{v}}=r_{\mathrm{v}}^{-1}$ (taken positive) is the curvature and where we have taken the excess pressure in the vein as zero, as discussed in Section 4.I.

The condition for growth of the lenses at the expense of the vein is $T_{1}<T_{\mathrm{v}}$ or, since $v_{\mathrm{w}}-v_{\mathrm{i}}$ is negative,

$$
p-p_{0}>\frac{v_{\mathrm{i}} \gamma\left(\kappa_{\mathrm{v}}+2 \kappa_{\mathrm{l}}\right)}{v_{\mathrm{i}}-v_{\mathrm{w}}} .
$$

Let us estimate $\kappa_{1}$ and $\kappa_{\mathrm{v}}$, taking Figure $7_{\mathrm{a}}$ as an example. The smallest visible lens has a diameter of $20 \mu \mathrm{m}$, which corresponds to $\kappa_{1}=28 \mathrm{~mm}^{-1}$. The size of the vein was measured as $d_{\mathrm{v}}=\mathrm{I} 9 \mu \mathrm{m}$ before the external load was applied, but a value of $23 \mu \mathrm{m}$ would be needed to account for the volume of water later seen in the lenses. We suspect a systematic error in the measurement and adopt $d_{\mathrm{v}}=23 \mu \mathrm{m}$, which corresponds to $\kappa_{\mathrm{v}}=2 \mathrm{I} \mathrm{mm}^{-1}$. The theoretical overpressure $p-p_{0}$ needed to prevent a $20 \mu \mathrm{m}$ lens freezing is then calculated from Equation (7) as $0.3 \mathrm{I}$ bar (taking $v_{\mathrm{i}}=1.09 \mathrm{~m}^{3} \mathrm{Mg}^{-1}, v_{\mathrm{i}}-v_{\mathrm{w}}=0.09 \mathrm{I} \mathrm{m}^{3} \mathrm{Mg}^{-1}$, $\left.\gamma=34 \mathrm{~mJ} \mathrm{~m}^{-2}\right)$. Under this pressure lenses larger than $20 \mu \mathrm{m}$ in diameter will grow. This is the excess pressure $p-p_{0}$ in the water lens rather than the applied uniaxial pressure $P$. $p-p_{0}$ is unlikely to be greater than $P$; it would be expected to be rather less because while a lens is growing the $10 \%$ decrease of specific volume on melting tends to relieve the pressure. In the experiment quoted $P$ was in fact $\mathrm{I} .3$ bar inclined at $20^{\circ}$ to the grainboundary normal, and it is satisfactory that this is not less than the value of $p-p_{0}$ calculated as necessary to make the visible inclusions grow.

\subsection{Time for formation of lenses}

We now calculate the rate at which the water lenses in a grain boundary might be expected to form under an applied stress. In Figure 7a many lenses, in two grain boundaries, form from a single vein. The main feature of the heat-flow problem is that heat is flowing outwards from a linear source into surroundings at a lower temperature. As a simple model, regard the vein as a cylinder of radius $r_{0}$ and replace the lenses by a larger concentric cylinder of radius $R_{0}$, with the temperatures of both cylinders given by Equations $(6)$ and (5). This may seem an excessively crude way of representing the water lenses in the two grain boundaries but, so far as extraction of heat from the vein is concerned, the main function of the lenses is to provide surroundings at a certain definite lower temperature. The solution to the problem is in fact insensitive to the value of $R_{0}$, as we shall see.

The (quasi-steady) temperature distribution around the vein is then

$$
T-T_{1}=\frac{d q / d t}{2 \pi k} \ln \frac{R_{0}}{r}
$$

where $d q / d t$ is the rate of loss of heat from unit length of the vein, and $k$ is the thermal conductivity. Putting $T=T_{\mathrm{v}}$ at $r=r_{0}$ we have

$$
\frac{d q}{d t}=\frac{2 \pi k}{\ln \left(R_{0} / r_{0}\right)}\left(T_{\mathbf{v}}-T_{1}\right)
$$


$d q / d t$ is related to the volume decrease of the vein and hence to the volume increase of the lenses, thus

$$
\frac{d q}{d t}=-L \frac{d V_{\mathrm{v}}}{d t}=L \frac{d V_{1 \mathrm{t}}}{d t}
$$

where $L$ is the latent heat per unit volume of water, $V_{\mathbf{V}}$ is the volume of unit length of the vein and $V_{1 \mathrm{t}}$ is the total volume of lenses associated with unit length of the vein. (As the vein shrinks it will cool and there is thus a component of $d q / d t$ due to specific heat, but a short calculation shows that this only becomes important when $r_{0}$ is of atomic size, when the continuum approximation has broken down anyway.) Using Equations (5) and (6) for the temperatures, we then have

$$
\frac{d V_{1 \mathrm{t}}}{d t}=\frac{2 \pi k}{L\left(s_{\mathrm{W}}-s_{\mathrm{i}}\right) \ln \left(R_{\mathrm{o}} / r_{\mathrm{o}}\right)}\left\{\left(v_{\mathrm{i}}-v_{\mathrm{W}}\right)\left(p-p_{\mathrm{o}}\right)-v_{\mathrm{i}} \gamma\left(\kappa_{\mathbf{v}}+2 \kappa_{1}\right)\right\} .
$$

$\ln \left(R_{0} / r_{0}\right)$ is insensitive to the precise values of $R_{0}$ and $r_{0}$. The width of the vein, and therefore $r_{0}$, varies by a factor of 3 during the growth of the lenses. Mean values are $R_{0}=300 \mu \mathrm{m}$ and $r_{0}=8 \mu \mathrm{m}$, which give $\ln \left(R_{0} / r_{0}\right)=3.6$. We shall regard $\ln \left(R_{0} / r_{0}\right)$ as constant.

The term $\left(v_{\mathrm{i}}-v_{\mathrm{w}}\right)\left(p-p_{0}\right)$ in Equation (8) promotes growth of the lenses while the term $v_{1} \gamma\left(\kappa_{\mathrm{v}}+2 \kappa_{1}\right)$ tends to diminish it. Let the lenses all be of equal volumes $V_{1}=V_{1 \mathrm{t}} / n$, where $n$ is the number per unit length of vein. As $V_{1}$ increases $\kappa_{1}$ decreases and $\kappa_{\mathrm{v}}$ increases. $p$ may also change, even though the applied stress is held constant, because of the change in volume associated with melting. The resulting time development of $V_{1}$ is therefore not quite straightforward; it could be analysed exactly for the case where $p$ is artificially held constant and is shown schematically in Figure 12.

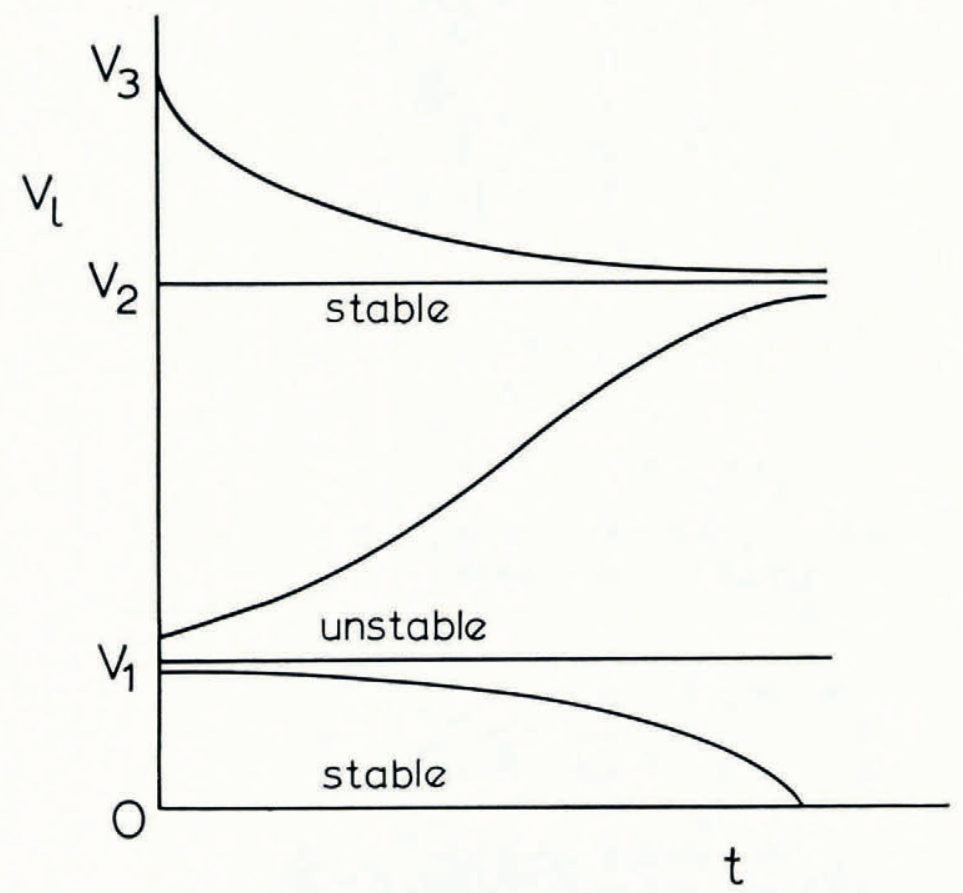

Fig. I2. The volume $V_{1}$ of a water lens as a function of time $t$ for various initial conditions with the pressure $p$ within the lens held constant. 
For $V_{1}$ less than a critical size $V_{1}, \kappa_{1}$ is large enough to make $d V_{1} / d t$ negative; the lenses freeze and disappear. For $V_{1}$ rather greater than $V_{1}$, the curvature term is less than the pressure term and $d V_{1} / d t$ is positive. But as the lenses grow the vein becomes smaller and $\kappa_{\mathrm{v}}$ increases. Eventually growth stops at $V_{1}=V_{2}$. If the lenses started with a volume rather greater than this they would shrink because of the associated high value of $\kappa_{\mathrm{v}}$. If all the water were in the lenses $V_{1}$ would equal $V_{3}$; the vein, being of vanishingly small size, has a very high curvature and the rate of decrease of $V_{1}$ is correspondingly high (in spite of the logarithmic factor). Thus the three equilibrium configurations are $V_{1}=0$ (stable), $V_{1}=V_{1}$ (unstable) and $V_{1}=V_{2}$ (stable). $V_{1}$ is the critical volume for nucleation of a lens.

To compare the time behaviour predicted by this model with that observed we cannot integrate Equation (8) because we are not sure at this stage what values of $p$ should be used. Instead write the right-hand side of Equation (8) as the difference of two terms arising from pressure and curvature, thus

$$
\frac{d V_{1 \mathrm{t}}}{d t}=\left(\frac{d V_{1 \mathrm{t}}}{d t}\right)_{\mathrm{p}}-\left(\frac{d V_{1 \mathrm{t}}}{d t}\right)_{\kappa}
$$

where

$$
\left(\frac{d V_{1 \mathrm{t}}}{d t}\right)_{\mathrm{p}}=\frac{2 \pi k\left(v_{\mathrm{i}}-v_{\mathrm{w}}\right)}{L\left(s_{\mathrm{W}}-s_{\mathrm{i}}\right) \ln \left(R_{\mathrm{o}} / r_{\mathrm{o}}\right)}\left(p-p_{\mathrm{o}}\right)
$$

and

$$
\left(\frac{d V_{1 \mathrm{t}}}{d t}\right)_{\kappa}=\frac{2 \pi k v_{\mathrm{i}} \gamma}{L\left(s_{\mathrm{w}}-s_{\mathrm{i}}\right) \ln \left(R_{\mathrm{o}} / r_{0}\right)}\left(\kappa_{\mathrm{v}}+2 \kappa_{\mathrm{l}}\right)
$$

and let us estimate $\left(d V_{1 \mathrm{t}} / d t\right)_{\kappa}$. The first factor $2 \pi k v_{\mathrm{i}} \gamma / L\left(s_{\mathrm{W}}-s_{\mathrm{i}}\right) \ln \left(R_{0} / r_{0}\right)$ is constant with the value $350 \mu \mathrm{m}^{3} \mathrm{~s}^{-1}$ (taking $k=2.2 \mathrm{~W} \mathrm{~m}^{-1} \mathrm{deg}^{-1}, L=330 \mathrm{MJ} \mathrm{m}^{-3}, s_{\mathrm{W}}-s_{\mathrm{i}}=\mathrm{I} .22 \mathrm{~kJ}$ $\left.\mathrm{kg}^{-1} \mathrm{deg}^{-1}\right)$. The second factor $\left(\kappa_{\mathrm{v}}+2 \kappa_{1}\right)$ varies during growth. It is large at the beginning ( $\kappa_{1}$ large) and end $\left(\kappa_{\mathrm{v}}\right.$ large) and smallest in between. To estimate its value during active growth of the lenses we have imagined first that all the lenses associated with the vein in Figure 6 are the same size, the average volume, and we have then calculated $\kappa_{1}$ at the time when they had achieved half this final volume; thus $\kappa_{1}=16 \mathrm{~mm}^{-1}$. If there is an equal volume of lenses in the second grain boundary and the total volume of water in vein and lenses is conserved, it follows that $\kappa_{\mathrm{v}}=25 \mathrm{~mm}^{-1}$, whence $\left(d V_{\mathrm{lt}} / d t\right)_{\kappa}=20 \mu \mathrm{m}^{2} \mathrm{~s}^{-1}$. $V_{1 \mathrm{lt}}$ grows from a negligible value to $180 \mu \mathrm{m}^{2}$ in about Ioo s, giving an average value of $d V_{1 \mathrm{t}} /$ $d t=\mathrm{I} .8 \mu \mathrm{m}^{2} \mathrm{~s}^{-1}$. Then from Equation (9) we deduce that $\left(d V_{1 \mathrm{t}} / d t\right)_{\mathrm{p}}=22 \mu \mathrm{m}^{2} \mathrm{~s}^{-1}$. This enables us to calculate $p-p_{0}$ from Equation ( 10 ) as 0.26 bar. It will be seen that the pressure term in Equation (8) exceeds the curvature term by only $10 \%$. If they were equal, so that the growth rate were zero, $p-p_{0}$ would be calculated as 0.23 bar.

We have found that the over-pressure $p-p_{0}$ needed to make the smallest visible lens grow is 0.30 bar while the over-pressure needed to explain the observed growth rate is 0.26 bar. In this example, as already mentioned, the applied compressive stress was 1.3 bar inclined at $20^{\circ}$ to the grain-boundary normal. Our estimates of $p-p_{0}$ are accurate enough to say that the over-pressure in the lenses is significantly less than the applied pressure. We have pointed out that as the lenses grow they and their immediate surroundings undergo a net decrease in volume, which to some extent relieves the over-pressure in them. If it were relieved so much that the over-pressure were reduced to the critical value (0.23 bar in the example) heat would cease to flow and growth would stop. The pressure could then build up again by creep in the surrounding ice. What actually happens is that the pressure is relieved to a slightly lesser extent than this. The process is self-regulating. The overpressure exceeds the critical value, perhaps by about $10 \%$; this produces a certain heat flow and hence a certain melting rate; at the same time the applied uniaxial stress, hindered 
by the over-pressure in the cavities, produces a rate of creep that is just sufficient to make the decrease of volume required by melting.

Let us look in a little more detail at the state of stress around the lenses. The circular edge of each lens, being of molecular sharpness, will tend to set up extremely high stress concentrations which must be relieved by creep. But the balance of surface energies does not allow the edge to be blunted by plastic flow (as would occur if it were not at a grain boundary). Presumably the only way in which the stress concentration can be relieved is by the stress in the ice immediately around the edge becoming biaxially hydrostatic, the two components in the plane normal to the edge being equal to the pressure in the lens. Since the lenses are fairly close together it seems likely that the over-pressure of about 0.3 bar calculated above is not confined to the immediate neighbourhood of each lens but extends throughout a region that embraces them all.

It is worth noticing that the applied stress will also cause transient creep in the vein. By the same argument the edges of the vein must remain sharp, and therefore the stress in their immediate vicinity must become biaxially hydrostatic. In ice under non-hydrostatic stress we must imagine tubes of biaxially hydrostatic stress surrounding all sharp edges where two grains meet a water phase.

This leads to a further point of interest. If one assumes, as we have done, that the two curved surfaces of a lens or the three curved surfaces of a vein constitute an isothermal, there is a problem, because the isothermal has infinite curvature at the sharp edges and this would lead to an infinite divergence of heat flow. The problem does not arise when the whole body is isothermal; it only appears when we begin to consider heat flow. In fact during freezing or melting the interface will not be exactly an isothermal, and the isothermals are presumably smoothly curved even at the sharp edge. The stress problem and the thermal problem at the edge are clearly closely connected.

\subsection{Absence of vein melting after the load is removed}

When the stress in Figure $7 \mathrm{a}$ is removed should we not expect the lenses to freeze and the vein to melt? In fact what happens is annealing: growth of the larger inclusions over a time of about $4000 \mathrm{~s}$ with almost constant volume of water in the inclusions. Thus, if the original state is eventually restored (which was not observed) the process clearly goes very slowly. From Equation (9), if the pressure term were absent we should have $d V_{1 \mathrm{t}} / d t=$ $-\left(d V_{1 \mathrm{t}} / d t\right)_{\kappa}$, and the curvature term would drive the heat back to the vein in about $9 \mathrm{~s}$. The fact that this does not happen must mean that, even though the external uniaxial stress is removed, there is nevertheless an over-pressure in and around the lenses of about $p-p_{0}=0.3$ bar because this is the value calculated above as necessary to bring the melting point of the lenses down to that of the vein. The source of this pressure must be the plastic deformation that took place while the lenses were forming to accommodate the $10 \%$ collapse of volume on the grain boundary. Nevertheless, the situation remains a little puzzling, because veins have lenses as close to them as the lens-to-lens distance, and our explanation therefore required a rather steep stress gradient around a vein.

A further point that we do not fully understand is that, when the load is removed, the lenses are cold because of over-pressure, and the vein is cold because of curvature; so heat should flow to both from the surface. This should tend to melt the lenses and so tend to relieve the over-pressure in them. It should also tend to melt the vein, without setting up additional pressure effects. The latter process is observed as a "rotting" of the veins when unstressed ice specimens are kept for long periods (weeks) at the melting point (private communication from M. E. R. Walford). It takes place surprisingly slowly in view of the supposed temperature differences. 


\subsection{Annealing time}

Our model for calculation up to this point has taken all the lenses the same size. We now relax this condition to calculate the rate at which the lenses might be expected to coarsen by the process described in Section 4.2.

Any one lens melts or freezes in the temperature (and stress) field of it and all the others. (For the reason given in the last Section the temperature of the vein is thought to be virtually the same as the average temperature of the lenses and so may be ignored in considering annealing.) This suggests that we should examine the behaviour of a single lens at temperature $T_{1}$ in surroundings that are at the average temperature $T_{\mathrm{m}}$ of the whole assembly of lenses. If $T_{1}>T_{\mathrm{m}}$ the lens will freeze at an increasing rate while the remaining lenses melt slightly. Thus $\tau_{\mathrm{m}}$ will decrease a little during the process, but for our purpose of estimating the rate at which the single lens freezes it is sufficient to take $T_{\mathrm{m}}$ constant.

If the lenses were all equal we suppose they would have $\kappa_{1}=\kappa_{\mathrm{m}}$, say, and $p=p_{\mathrm{m}}$, say; thus, from Equation (5)

$$
T_{\mathrm{m}}-T_{0}=\frac{v_{\mathrm{i}}}{s_{\mathrm{w}}-s_{\mathrm{i}}} 2 \gamma \kappa_{\mathrm{m}}+\frac{v_{\mathrm{w}}-v_{\mathrm{i}}}{s_{\mathrm{w}}-s_{\mathrm{i}}}\left(p_{\mathrm{m}}-p_{\mathrm{o}}\right),
$$

and, by subtraction of this equation from Equation (5),

$$
\tau_{1}-T_{\mathrm{m}}=\frac{v_{\mathrm{i}}}{s_{\mathrm{w}}-s_{\mathrm{i}}} 2 \gamma\left(\kappa_{1}-\kappa_{\mathrm{m}}\right)+\frac{v_{\mathrm{w}}-v_{\mathrm{i}}}{s_{\mathrm{W}}-s_{\mathrm{i}}}\left(p-p_{\mathrm{m}}\right) .
$$

If the lens is approximated as a sphere the temperature distribution around it is

$$
\tau-\mathcal{T}_{\mathrm{m}}=\frac{d Q / d t}{4 \pi k} \cdot \frac{\mathrm{I}}{r},
$$

where $d Q / d t$ is the rate of loss of heat. On the surface of the sphere $r=r_{1}$, say, $T=T_{1}$ and so

$$
\frac{d Q}{d t}=4 \pi k r_{\mathrm{I}}\left(T_{1}-T_{\mathrm{m}}\right)
$$

If $V$ is the volume of the lens, $d Q / d t=-L d V / d t$; hence using Equation (I2)

$$
\frac{d V}{d t}=-\frac{4 \pi k r_{1}}{L\left(s_{\mathrm{w}}-s_{\mathrm{i}}\right)}\left\{2 v_{\mathrm{i}} \gamma\left(\kappa_{\mathrm{l}}-\kappa_{\mathrm{m}}\right)-\left(v_{\mathrm{i}}-v_{\mathrm{w}}\right)\left(p-p_{\mathrm{m}}\right)\right\}
$$

Let us ignore, for the moment, any pressure difference $p-p_{\mathrm{m}}$ and in representing the lensshaped inclusion by a sphere put $r_{1}=\frac{1}{2} \kappa_{1}^{-1}$, roughly. Then

$$
\frac{d V}{d t}=-\frac{4 \pi k v_{\mathrm{i}} \gamma}{L\left(s_{\mathbf{W}}-s_{\mathrm{i}}\right)}\left(\mathrm{I}-\frac{\kappa_{\mathrm{m}}}{\kappa_{1}}\right) \text {. }
$$

The variable term $\left(\mathrm{I}-\kappa_{\mathrm{m}} / \kappa_{\mathrm{l}}\right)$ is zero if $\kappa_{\mathrm{l}}=\kappa_{\mathrm{m}}$ and approaches $\mathrm{I}$ as $\kappa_{\mathrm{l}} \rightarrow \infty$. An average value of $d V / d t$ is therefore

$$
-\frac{2 \pi k v_{\mathrm{i}} \gamma}{L\left(s_{\mathrm{w}}-s_{\mathrm{i}}\right)}
$$

So lenses that are smaller than average might be expected to disappear in a time of about

$$
\frac{L\left(s_{\mathrm{w}}-s_{\mathbf{i}}\right) V_{1}}{2 \pi k v_{\mathrm{i}} \gamma}
$$

The mean volume $V_{1}$ of a lens in Figure $7 \mathrm{a}$ is $4400 \mu \mathrm{m}^{3}$, which gives a time of $3 \mathrm{~s}$. This is much less than the observed time of $4 \times \mathrm{IO}^{3} \mathrm{~s}$ for the coarsening of the lens pattern. 
The slowness of the observed rate must be due to pressure differences between the larger and smaller lenses, which were ignored in the calculation. To reduce the rate by the necessary factor of $\mathrm{IO}^{3}$ the temperature difference must be reduced by the same factor. This means that the difference in melting point arising from curvature must be almost $(99.9 \%)$ balanced out by the effect of differential pressure. Thus, from Equation (13)

$$
p-p_{\mathrm{m}}=\frac{2 v_{\mathrm{i}} \gamma}{v_{\mathrm{i}}-v_{\mathrm{w}}}\left(\kappa_{1}-\kappa_{\mathrm{m}}\right) \text {. }
$$

In the example of Figure $7 \mathrm{a}, \kappa_{\mathrm{m}}=13 \mathrm{~mm}^{-1}$ and a typical value of $\kappa_{1}$ is $\mathrm{I} 7 \mathrm{~mm}^{-1}$, giving $p-p_{\mathrm{m}}=0.03$ bar. This quite small pressure difference is enough to slow annealing down by the necessary factor of $10^{3}$.

We concluded in Section 5.4 that the average over-pressure in the lenses after removal of the external load was $p_{\mathrm{m}}-p_{0}=0.3$ bar. Therefore, our picture now is that the overpressures $p-p_{0}$ in the individual lenses are in the range $0.3 \pm 0.03$ bar. The material in the general neighbourhood of the lenses is under a pressure $p_{\mathrm{m}}$ from the plastic constraint of its surroundings. The individual lenses have pressures $p$ slightly greater and less than this, and they undergo plastic expansion and contraction accordingly, of amounts just sufficient to accommodate the volume changes. It is understandable that the differential pressures in the cavities are quite small: a small over- or under-pressure is very effective in causing volume change, because, on the one hand, the cavity tends more to a disk-shape than a sphere and, on the other hand, it has a sharp edge that promotes plastic deformation. The situation is very different for a single water lens and for a whole group of them, for we have seen that a whole group can exert an over-pressure of 0.3 bar in their general neighbourhood without causing a noticeable creep rate.

The fact that the pressure even in the largest lenses is some $\mathrm{I} \cdot 3$ bar (atmospheric plus 0.3 bar) is consistent with the observation that they contained no water vapour.

\section{Formation of Water Lenses in a flowing glacier}

We may ask whether such water lenses will form in a temperate glacier, with corresponding constriction of the veins. If the process we have discussed is to operate there must be, of course, a departure from hydrostatic pressure. The ambient pressure $p_{0}$ in the experiments happens to be atmospheric, but one could equally well contemplate the effect under any greater ambient pressure. The departures from hydrostatic pressure present in a glacier by reason of its weight are of the same order of magnitude ( $\mathrm{I}$ bar) as those used in the experiments. The most significant difference from our experimental conditions probably occurs in the deepest layers of temperate glaciers where the veins are in communication with the atmosphere only through lengths of $100 \mathrm{~m}$ or more. As we have already noted in Section 4. $\mathrm{I}$ this means that the pressure in them could be raised by a uniaxial compressive stress, in contrast to our experiments where the veins are close enough to the surface for the pressure in them to remain unchanged. The important question then is whether a uniaxial compressive stress raises the pressure in a grain-boundary lens more than it does in a vein; for, if it creates an equal pressure in both, the process we have discussed will not operate. It is a very difficult problem in plastic creep, as we have suggested, to calculate these overpressures, especially because of the changes in volume that accompany melting and freezing. Nevertheless, in order simply to decide whether the process operates or not we might argue as follows.

Suppose a lens and a vein existed as in Figure 8a, initially quite free from internal stresses, and suppose a uniaxial compressive stress $P$ were then applied. The over-pressure in the lens, whose faces are nearly perpendicular to the stress axis, would presumably become $P$, to a good approximation. The over-pressure in the vein, thought of now as being closed, is 
less easily estimated, but a reasonable guess would be the mean of the three principal applied stresses $(P, \mathrm{o}, \mathrm{o})$ that is $\frac{1}{3} P$, or possibly $\frac{1}{2} P$. It would be unreasonable to think it would be as high as $P$, because this is the value it would take if the applied stress were $(P, P, P)$ with two additional components. Therefore there would initially be a greater over-pressure in the lens than in the vein. If $P$ were high enough the lens would begin to grow, but, at once, the volume changes produced by melting and freezing would relax the over-pressures in such a way as to slow down the process. We cannot calculate how much the pressures would relax, but the essential point we may infer from our previous discussion is that although this relaxation will slow the growth it will not stop it entirely.

We conclude that the effect seen in the laboratory will also occur in a temperate glacier. The lenses may grow slightly more slowly, but in a glacier there is plenty of time available.

\section{Substances other than ice}

The sign of the pressure-melting point relation in ice is of course abnormal, but there seems no reason why the effect discussed in this paper should not exist as the general rule for all pure polycrystalline solids at their melting points, when the dihedral angle $2 \theta$ in the liquid phase lies in the appropriate range $o^{\circ}$ to $60^{\circ}$, provided that pressure is replaced by tension and vice versa. Thus liquid lenses ought to be expected in grain boundaries at right angles to an applied tension and in boundaries parallel to an applied compression. This may have geophysical implications when taken in conjunction with the Frank (1968) theory of the up-welling of the liquid phase in the rocks of the Earth's mantle.

\section{Acknowledgements}

We thank Miss E. M. Morris for her help in the initial stages of this work and Dr M. E. R. Walford for his useful advice. Professor F. C. Frank kindly read and commented on the paper; we have adopted a number of his suggestions. One of us (S.M.) is indebted to the British Council, which enabled him to carry out this work by providing a two-year scholarship.

MS. received 6 July 1971 and in revised form I 7 September 1971.

\section{REFERENCES}

Barnes, P., and Tabor, D. 1968. Plastic flow and pressure melting in the deformation of ice I. Union de Géodésie et Géophysique Internationale. Association Internationale d'Hydrologie Scientifique. Assemblée générale de Berne, 25 sept. -7 oct. 1967 . [Commission de Neiges et Glaces.] Rapports et discussions, p. 303-15.

Frank, F. C. I968. Two-component flow model for convection in the Earth's upper mantle. Nature, Vol. 220, No. $5^{165}$, p. $35^{0}-5^{2}$.

Ketcham, W. M., and Hobbs, P. V. I969. An experimental determination of the surface energies of ice. Philosophical Magazine, Eighth Ser., Vol. 19, No. 162, p. 1161-73.

Lliboutry, L. A., 1971. Permeability, brine content and temperature of temperate ice. Fournal of Glaciology, Vol. 1o, No. 58, p. 15-29.

Nye, J. F., and Frank, F. C. In press. The hydrology of the intergranular veins in a temperate glacier. Union Géodésique et Géophysique Internationale. Association Internationale d'Hydrologie Scientifique. Commission de Neiges et Glaces. Symposium on the hydrology of glaciers, Cambridge, 7-13 September 1969 , organized by the Glaciological Society. 